\title{
The Conceptual Framework of Articulated Human Intelligence in Perspective of Industry 4.0
}

\author{
Abhay Saxena ${ }^{1}{ }^{*}$, An-Yuan Chang ${ }^{2}$, Narayanan Kulathuramaiyer ${ }^{3}$ and Ashutosh Bhatt ${ }^{4}$ \\ 1Dev Sanskriti Vishvavidyalaya, Motichur Range - 249411, Uttarakhand, India; abhaysaxena2009@gmail.com \\ ${ }^{2}$ National Farmosa University, Yunlin County, Taiwan; ayc@nfu.edu.tw \\ 3ISITI, UNIMAS, Malaysia; narayanan.kulathuramaiyer@gmail.com \\ 4Birla Institute of Applied Sciences, Bhimtal - 263136, Uttarakhand, \\ India; ashutoshbhatt123@gmail.com
}

\begin{abstract}
Objective: The world of Artificial Intelligence is enormous and so is the technological intervention in making a sophistical machine. The machine is professing about sentiments, beliefs and emotion. The Robots had outclassed human being in terms of knowledge, performance and now in the soft world of emotions. The Industry 4.0 is the world of cyber physical world where everything is likely to revolve around the Machine and cyber space. The sustenance of human being into this sophisticated cyber world is questionable. We have no other option than to evolve more smart, competitive and efficient human being.The research talks about "Articulated Human Intelligence". Methods/Analysis: Research study deals with a framework of Articulated Human Intelligence. Findings: This research study is proposinga new version of A.I, Internet of things, Big Data analytics, Additive manufacturing in human perspective. Novelty/Improvement: The proposed work will help to redefine Artificial intelligence as Articulated Human Intelligence.
\end{abstract}

Keywords: Articulated Human Intelligence, Big Data Analytics, Industry 4.0, IoT, Worker 4.0

\section{Introduction}

The world of Robot is enormous and so is there presence in the living world. From Sophia to the corporate ladder, they are showing tremendous presence in terms of productivity and retention rate. In a surprising motion, the multi tasker bot is performing tremendous and likely to replace entire team. And recently, Google won a patent to start building worker robots with personalities. The intelligent machines are now on a definite move and looks more sophisticated, specialized as compare to the earlier version Siri and Roomba. Now we can say that we entering in the new era of machine which can be dominant by the industry $4.0^{1}$.

\section{Need of the Study}

The human Growth is questionable and it looks this evolution theory is like to take into the reverse direction and we are just heading towards evolution rather Devolution. We are moving back to the origin and in the time frame it looks we are not finding the elevated and wisdom oriented souls. Like on earth.

The present scenario clearly indicates that the human values are on downfall and so is the quality of life. It looks that the immortality of the Human being is being achieved and now the scientists are talking about the life of human being very much like immortal Devtas? "The first person to live to be 1,000 years old is certainly 
alive today ${ }^{3}$. "I am working on immortality", Professor, University of California, who has achieved breakthrough results extending the lives of fruit flies. "Twenty years ago the idea of postponing aging, let alone reversing it, was weird and off-the-wall. Today there are good reasons for thinking it is fundamentally possible."

\section{Industry 4.0 and Industry Worker 4.0}

Industry 4.0 states to the use of automation and data exchange in manufacturing. As per the theory of Boston Consulting Group in industry 4.0, it consists of nine main technologies like Autonomous Robots, Simulation, Horizontal and Vertical System Integration, the Industrial Internet of Things, Cybersecurity, The Cloud, Additive Manufacturing, Data and Analytics, and Augmented Reality ${ }^{4}$.The two different approaches of machine / man evolution are as shown in Figure 1.

A way where the man was thinking to rule the world and made machine to help and assist in day to day life. Man had developed Artificial Intelligence (A.I.), Robotics, Fuzzy logics, various aspects of soft computing to have a sophisticated servant in the form of machine. The parallel processing to evolve machine from Man and to evolve Man from Machine are going on simultaneously. "Manwith-machines" evolution is known as Worker $4.0^{5}$. Intuit predicts that by 2020, 40 percent of American workers will be independent contractors. Now question arises what are the traits that industry worker 4.0 will possess? It looks to be flexibility in working, creativity in thoughts, resourcefulness in terms of execution of the job and above all is the vast experience - natural or artificial.

Rather people are talking now about human and machine partnership. AI cannot create new knowledge or valid new scientific context, and cognitive advancement is limited by certainty of context. A human must create the necessary data structure and training routines to impart

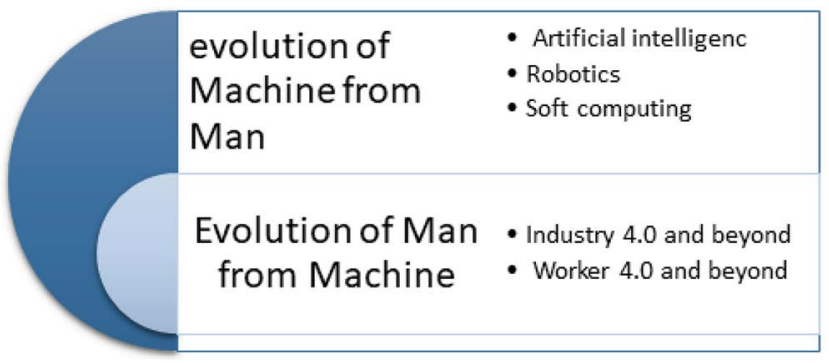

Figure 1. Machine and man evolution. information to the machines, empowering its patternrecognition capabilities ${ }^{6}$. If one looks around the world, the numerous efforts are already in process to have a new version of human being. If we discuss the cutting edge of the Transhumanist movement, where hackers, engineers, artists, programmers, and others are working to shape the next phase in human evolution ${ }^{7}$. The fourth wave of Industrial revolution is creating havoc. Machine has attained vision and emotions but how about the human values and environment conditions. The security of the society will be on stack. It is emotional recreation which is likely to decide the human destiny ${ }^{\underline{8}}$. The gap between human and machine functionality is easily visible and with we will try to understand the same with some case studies.

Case I: A machine is driving a car and all of sudden it found two obstacles i.e. a matured human being and a baby. Now the situation is something where either of them are likely to be hit by the car. The machine is to decide whom to hit first-big object or small (in this case both are human being). May be the machine is likely to take the decision on the Size of the object which is shorter or bigger, the damage that may cause by a small object or bigger or impact on the car after accident from shorter or bigger object or in random action either of them. More likely, the machine is to hit the baby as he is smaller in size, less damage and minimum impact on car after accident. But as a human being we would like to save the younger one first.

Case II: We are in the class of students in which machine and students are learning all together. Machine all of sudden gets up from its chair and give a tight slap to the student all because of student attitude, behavior or any misunderstanding. How we are likely to take this case. What are the rules that are going to govern into this scenario? A normal student rules are not likely to be fit in for the machines. A teacher doesn't know how to make the machine to behave like human or in worst case the teacher himself can be a victim of machine.

Case III: We had trained a group of machines as soldier, with all sets of knowledge of arms and ammunition. It all goes well and machines became perfect soldiers. Later we had given them ethics and moral values training so as to make them ready to serve the society. All of sudden while working on a civilian front, one machine is behaving like a suicide bomber. It is likely to take revenge of all these hard training and sophisticated human values. Now, how 
to cordon down this machine will be a real challenge. We had been trained to combat human terrorist but how about the machine as a suicide bomber.

There are a number of cases where we, the human beings are yet not prepared. Neither we had a thought to take these cases, nor we have any strategy to deal with this inhuman activity of machine.

\section{Proposed Work}

While going through the current scenario, machine had outclassed human being. The machine performance, calculation, adaptability of technology and deliverance is unparalleled and the human fear to lose the job is on high node. The industry is likely to face a cut short of job opportunities seriously. 5.1 million jobs are expected to disappear over the new five years in 15 leading countries due to robotics application?. Contrary, had replaced robots with human being in assembly line. "Robots can't deal with the degree of individualization and the many variants that we have today," said the company's head of production Markus Schaefer ${ }^{10}$. The Reason is bit simple as the machine can automate the process effectively but customization of the product based on the customer requirement is yet to be understand by Robots.Here, there are two voices in the society. One is appreciating the smart machine intelligence and another is complaining about the machine and its dominance into human world. We have no other option than to make a human being more smart, competitive and efficient in this cyber physical world. How the ordinary man is likely to sustain himself into this sophisticated cyber world looks to be a real challenge? We are proposing herewith another segment of the solution for this problem is to design a set of Machine intelligence to support the existing human being. We can label it as a Humanoid Intelligence to support human being. We are proposing an Additional set of machine intelligence to raise the understanding, performance and adaptability of the human being.

\section{Machine Intelligence to Support Human Being}

So how, this additive machine intelligence is likely to help the human being is a real question. The machine intelligence is likely to help the human beingin: Mental cognition (a way through which the inflow of thoughts, sentiment can be channelized and regulated properly),
Intuition (where the Individual can foresee the things without getting carried out), Problem solving skills (creative and analytical), Situational adaptability (deliberated or willing full), Control (situational or predefined) Communication (with man and machines).

What are the qualities this Articulated Human Intelligence based Human Being possessed will be the next question? Whether we are jumping into a new controversy or it will be a new set of A.I, IoT, Big Data analytics, Cyber Security, Additive manufacturing, cloud computing and simulation is likely the matter of debate. Our proposition says that the articulated Human Intelligence will replace the existing artificial intelligence. It will have a definite solution for all the ingredients of Artificial Intelligence.The Articulated Human Intelligence will infuse human phenomena in machine. The basic concept is also discussed in Figure 2.

\subsection{Simulation can be Replaced with}

\section{Samvedana}

Simulation is an environment where we would like to replicate the existing environment and one can feel it in realistic environment. The Samvedna (the feel, compassion can make the machine more on humanistic ground).

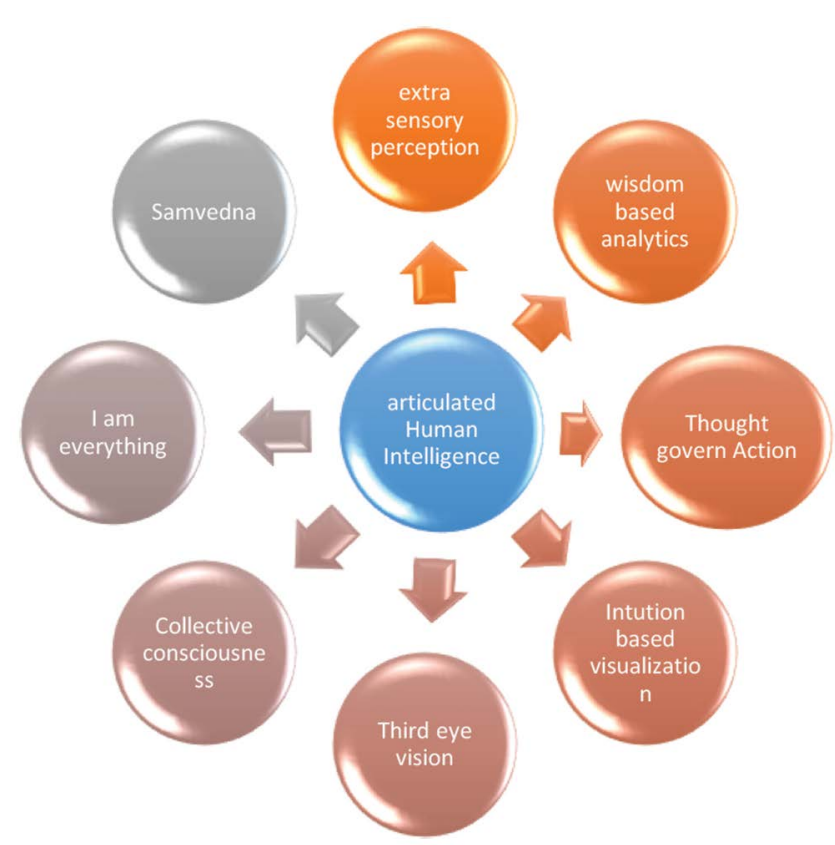

Figure 2. Proposed framework of Articulated Human Intelligence. 


\subsection{Internet of Thing can be Replaced with} Intuition, or with "I am everything (Aham Brahmasmi)"

The Internet of thing is on a high tide ride and very soon it will be a world full of machine sensor's all around. However, if we can make the machine to understand the Vedanta sutras like (I am that- the lord), (I am the shiv) then it will deliver more likely on Humanistic approach and Believe.

\subsection{Cloud can be Replaced with Collective}

\section{Consciousness}

The world of cloud is enormous and its virtual presence is unparalleled. However, if we can make the machine to understand that it is not a matter of individual consciousness, rather this world, is a show of collective consciousness. Moreover, if we can train the machine with a definite set of collective consciousness, the machine's behavior and performance will be more on Humanistic side.

\subsection{Augmented Reality with Trinetra (Third Eye Vision)}

With the advent of the Augmented Reality, the virtual world is more live, vibrant and multi-dimensional in nature. The 3-D to 7-D world had changed the definition of live feel. Now if we can equip and train the machine with Trinetra (Third eye vision), to foresee the things in subtle world or things more likely to happen in near future, then it will give an additional dimension to the machine intelligence and to serve the human being more effectively.

\subsection{Additive Manufacturing can be Replaced with Intuition based visualization}

Additive manufacturing has given us 3D printing, rapid prototyping and Direct Digital Manufacturing. It is a new and innovative way to get the customized product and if we can have trained the machine with Intuitive Vision development, then the performance of the machine will be more likely to be on a human perspective.

\subsection{Autonomous Robot will be Replaced with Thought Govern Actions}

The Bots are changing our life; rather they are cornering us to just wait and watch. There action, understanding and performance is just unparalleled and it is a serious challenge for the human existence. Now if we can equip the machine to be worked on a thought govern network, it will add up a new dimension for the machine and it will perform very similar as human being. The control and execution of thoughts will make the machine to perform better and more to be in control of human being.

\subsection{Big Data Analytics can be Replaced with Wisdom based Analysis}

The cyber world is working more or less on Big Data analytics. The ever increasing terabyte data needs to be analyzed on regular basis and the tools are either catering the problem of storage or query / analysis. Now if we can make the machine to take query, decision and analysis based on wisdom, then the machine will performance will be similar to human being and it can also resolve the discrimination in no time.

\subsection{Cyber Security can be Replaced with Extra Sensory Perception}

The cyber world is a real challenge especially in terms of security is concerned. It is always a field where threats are vulnerable in nature all because of horizon and covered area is concerned. However, if we can train the machine with extra sensory perception, then it can foresee the cyber issues well before it is likely to happen in the realistic environment. This will surely save the time, space and efforts as well as machine can help the human being more effectively.

\section{Probable Outcome}

We have to redefine the languages of A.I. in terms of Human Intelligence. We had createdsophisticated machines for the man. Now it is the time to redefine and redesign the machine to assist human being. This will surely give an edge to the human being to compete and challenge machine into this Industry 4.0 world.

\section{Conclusion}

The world of Artificial intelligence is enormous and ever growing. It is a complicated machine centric world and all we need is to redefine the same, in such a way where the human being can also feel to be a part of it. The 
phenomenal changes in terms of knowledge sustenance, bulk production and sustenance in this Cyber physical world is a real challenge for human being and our proposed work will really help to redefine Artificial intelligence as Articulated Human Intelligence.

\section{Future Scope}

The future scope of the articulated human intelligence and Industry 4.0 is enormous. We had proposed the framework of this Articulated human intelligence and our next step will be to redefine simulations, A.I., Additive manufacturing, Big Data Analytics in this new perspective. However, we can also think to work on Humanoid Psychology in near future.

\section{Acknowledgement}

We are likely thankful to Dr. Chinmay Pandya, Pro Vice Chancellor, Dev Sanskriti Vishwavidyalaya for his insight vision on shaping this research paper.

\section{References}

1. The 12 principles of the Pyong'hwa. Available from: https:// www.balboapress.com/BookStore/BookDetails/379517The-12-Principles-of-Pyong-hwa
2. Ritual, State, and History in South Asia. Available from: https://brill.com/view/title/772

3. The man with machine evolution has begun. Available from: https://www.bridgepartnersconsulting.com/insights/ man-with-machines-evolution-has-begun

4. An evolving partnership: The future of man and machine. Available from: https://www.cas.org/blog/evolving-partnership-future-man-and-machine

5. To be a machine, will the next stage of human evolution will be digital. Available from: https://www.unboundworlds. com/2017/03/machine-will-next-stage-human-evolutiondigital/

6. Robots, new working ways to cost five million jobs by 2020, Davos study says. Available from: https://www. reuters.com/article/us-davos-meeting-employment/ robots-new-working-ways-to-cost-five-million-jobs-by2020-davos-study-says-idUSKCNOUWONV

7. Mercedes replaced robots with people on its assembly line. Available from: https://www.engadget.com/2016/02/25/ mercedes-benz-replaces-robots-with-humans/

8. Rentzos L, Mavrikios D, Chryssolouris G. A two-way knowledge interaction in manufacturing education: The teaching factory. Procedia CIRP. 2015; 32:31-5. https://doi.org/10.1016/j.procir.2015.02.082

9. Benešová A, Tupa J. Requirements for education and qualification of people in industry 4.0. Procedia Manufacturing. 2017; 11:2195-202. https://doi. org/10.1016/j.promfg.2017.07.366

10. What you need to lead in Industry 4.0. Available from: https://www.humanresourcesonline.net/what-you-needto-lead-in-the-industry-4-0/ 